\title{
THE MAKING OF PUPILS: INSTITUTIONALIZED EDUCATION IN ROMANIAN HIGH SCHOOLS
}

\author{
MARIA MARTELLI ${ }^{1}$
}

\begin{abstract}
This article aims to explore the ways in which power structures the learning experience in high school, detailing what kind of cultures it creates and what practices it fosters. By interviewing students (currently enrolled in the Faculty of Sociology and Social Work, Cluj-Napoca) recalling their high school years, I can tap into their reflexivity regarding the experiences of being taught to and of learning, focusing especially on how these have become legitimated and have formed the subject. Drawing on Paulo Freire's theory of the banking model and using a post-structuralist framework, the research intends to make visible a current account of institutionalization of learning. Finally, the research shows how pupils become subjects to be categorized according to their compliance to the programme's requirements and how they might internalize legitimized forms of learning (such as memorizing for further testing) in detriment of others.
\end{abstract}

Keywords: institutionalized learning, education, high schools, power, ethnography

\section{Introduction: institutionalized learning in Romanian high schools}

How do public educational institutions shape pupils' relationship with learning and knowledge? This article aims to describe experiences of high school in Romania by looking at what is not usually made visible: the use of power and the learning that slips past the institution's control. The main argument is made in regard to institutional power, which has the legitimacy to set the standards of acceptable and desirable knowledge. Therefore, the creation of an institutionalized learner takes place within given power structures: a self that is built upon by educational practices and that is best known and accounted for by the system. Theoretically, the research draws its roots from critical pedagogy, inquiring into whether, and how, Paulo Freire's (2000) banking model is still used in high schools. The method of research has been qualitative, as this

\footnotetext{
1 Faculty of Sociology and Social Work, Babeș-Bolyai University, e-mail: Maria.martelli@yahoo.com.
} 
is appropriate when looking to unveil personal experiences of encountering knowledge and of processing truths. From the interviews, as empirical data was being collected, ethnographic details of the construction of pupils and knowledge was overflowing. This process was strongly influenced by the dynamics of power, both over processes of learning and their labels. It is thus by going towards Michel Foucault's (1995) analysis of disciplinary discourse that much of what happens in classrooms can be understood. Institutional order as a site for power to be manifested is exposed, with its capacity not only to organize, but to define and 'make' pupils.

\section{Framing high school learning: theories for the classroom context}

Detailing classroom experiences of learning in Romanian high schools is one step towards better understanding their inner workings. This article aims to provide such descriptions (e.g. of how teaching is perceived, of choices of examination, of teacher-student relationships), along with a theoretical framing that is particularly attentive to the micro-dynamics of power, but does not ignore the macro-dynamics, such as the socio-economic context.

To begin with, power appears to strongly shape the space into which education happens. This paper explores how power is used upon a pupil depending on the kind of high school he/she is enrolled in (well performing or underperforming according to national standards). It also looks at how discipline is internalized, both of body and of mind. It is often that in Romanian high schools, teachers expect a mind that listens, pays attention, writes carefully, remembers. Institutionalization starts since primary school, where the pupil encounters the 'setting' of desks, one behind the other, with the teacher in front. A parallel is to be made with Foucault's (1995) description of how soldiers' bodies are disciplined: there is an act of enclosure within the classroom as well and there is often a particular place ascribed for a particular pupil. The site is made to be functional, easy to supervise and control, rank is less visible, but exists in the tacit knowledge of who is 'good' as a pupil and who isn't. This 'made the educational space function like a learning machine, but also as a machine for supervising, hierarchizing, rewarding' (Foucault 1995: 147). Time is subjected to power, by subscribing to a pre-determined time table and, within each class, a predetermined programme of teaching. Duration is divided and a succession of simple elements, as bits of knowledge partitioned in lessons, is given. An examination is to conclude these operations, which 'will have the triple function of showing whether the subject has reached the level required, of guaranteeing that each subject undergoes the same apprenticeship and of differentiating the abilities of each individual' (Foucault 1995: 158). In such a climate, profound 
learning becomes a difficult aim to attain. The national exam at the end of high school, (the baccalaureate) is an optimal example: learning is perfectly distributed in bits, of which the most important part often is understanding what is asked, what exactly the problem is, and how it is required to solve it. It is constructed as an exam of spectacular importance, thus becoming quite stressful, although research (Vogel \& Schwabe, 2016) has shown that stress impairs learning, making it rigid, habit-like behaviour (as opposed to flexible learning, which enables memories to easily adapt to new information). Possibly related, pupils seem to become less and less content with school as they grow and get closer to 12th grade. Bălățescu (2009) shows this in his research on school satisfaction in Romania. Apparently, contentment is highly influenced by the social atmosphere inside the high school. Pupils seem most dissatisfied with school (from a series of other variables such as family life, friendships, etc.), and within it, with their own results and their relationship with the teachers. As my research makes note of those as well, the best part of school seems to be being friends with your classmates.

Post-socialist Romanian schools are sites onto which many pressures are being put: locally, from the main actors involved in the educational setting (teachers, pupils and parents), and nationally, from a neoliberal tide of discourses and practices in an Eastern European context. The overall transition from a communist political regime has brought about many changes, including over what is a desirable life course, and what norms and values are to be practiced in an institution. Stanciulescu (2002: 31) looks at how values are being negotiated, from the individual ones to the institutional and how norms of 'saving face' are put in front of institutional needs. In this transition, teachers are put in political positions they become flexible towards, out of need of preserving their job and status (2002: 153). Grasping and maintaining the power they do have becomes thus quite important. An approach that looks directly at the flows of power between pupils and teachers/institutions is rarely encountered in the scientific literature on education in Romania, which tends to be more about understanding macro-structures or very specific discipline related phenomena. However, a national study (Iosifescu et al, 2013) on cultures of quality applied the Hofstede model, which might bring some insight. The model looks at organisational culture in four dimensions, distance from power, individualism/collectivism, femininity/ masculinity and uncertainty avoidance. Even if at least part of the study is problematic (for example the assumption of a feminine/masculine dimension), the first and the last dimensions are of particular relevance. The results show that there is a general acceptance of authority and its legitimacy, especially among pupils and parents. The same study, when undertaken in 2002, concluded that parents educated their children to be docile and that children were used to being 
told what to do and to waiting for instructions from the 'wise' teachers. Hofstede's dimension of uncertainty avoidance shows that there is a need for well-defined rules and a preference for dealing with fixed problems. This predilection tends to leave little to no freedom to the pupils.

Each individual's position in the social field affects his/her educational experience in multiple ways. The concept of habitus is relevant, as it refers to embodied social structure: each individual has internalized certain practices that are made visible by how one moves, talks and conceives the world around him/her. Because 'individuals do not move about in social space in a random way', there is a 'field of the possibilities objectively offered to a given agent' (Bourdieu, 1984: 110). Habitus is embodied into the individual, it becomes part of him/herself and of his/her life trajectory, and thus enables the reproduction of the same social position through generations. A particular example of how social reproduction happens through education is given by Jean Anyon's research (1980) of high schools of different types. It shows how schools themselves structure their teaching styles according to pupils' social class, categorized based on parents' occupations. Working class schools invest energy in discipline and controlling children's movements, teaching itself being an inventory of rules to follow. Middle class schools require pupils to answer factual questions and 'store facts up in your head like cold storage' (respondent from the paper by Anyon, 1980: 79). Affluent professional schools (where parents' occupations are lawyers, executives, cardiologists) ask for independent and creative thinking, with control based on negotiation rather than giving orders, and elite schools (where fathers are top executives) demand the development of analytical thinking and reasoning through problems. Anyon's research helps shed light on school differences in Romania as well, as the instructive practices of teachers are, at times, similar, and pupil's aspirations are fitting to their standing in the given fields.

Succeeding, or doing well, in high school, often requires playing a particular part that one has to learn. A pupil may be taken by the act, or become cynical of it: he/she might believe in the purpose and usefulness of schooling in that particular manner, or might see how it fails, and look for ways of coping. More of an act is required of pupils that are considered 'good', as they must always appear prepared, both having worked hard and being at ease. This is most interestingly explored in Gaztambide-Fernández's (2011) ethnography of an elite high school. He writes about how pupils tend to 'bullshit', namely 'find what the teacher likes, even though you don't like it yourself, and just to get that better grade. That's the name of the game' (respondent from the paper by GaztambideFernández, 2011: 583). In this study, learning 'how to talk' and 'how to talk your way out' are closely related, and, one understands that, in the context of 
demanding education, learning goes hand in hand with learning what exactly the institution wants from you, and how to give it. From a cultural anthropological point of view, this can be interpreted as a cultural event, classroom learning being procedural display: 'a set of interactional procedures which themselves count as doing a lesson' (Bloome, Puro \& Theodorou, 1989). Doing school is thus a sort of mechanical play on the common understanding of what accepted practices are, for both teacher and pupil, and the community at large. Pupils learn how to enact learning. This becomes transparent both when listening to live classroom practices (as Bloome et al. did), and when paying attention to how they recall past learning experiences (as explored in this article). Sometimes knowingly, other times without realizing, teachers often engage in what Paulo Freire calls 'banking education' (2000). The subject-authority of knowledge is the teacher and pupils are listening objects, ready to be filled with words and concepts. Reality appears motionless and neatly compartmentalised. Education becomes 'an act of depositing'. In Henri Giroux's terms, who expands on Freire's work, this 'type of pedagogy celebrates rote learning, memorization, and high-stakes testing' (Giroux, 2011: 18). It is though knowledge that one can have a better grasp over one's own self and place in society, but by being educated in a banking model way, this power is not given to pupils.

\section{Structuring high-school experiences of learning}

Two major dimensions of my research are the flows of power and the wide array of factors that influence learning beyond the institutionalized curriculum (what I call 'the human dimension'). By 'flows of power', I mean the way the power to define the educational setting is held and acted through, most often, but not always, by teachers. This power 'flows' towards higher authorities or even towards students themselves, because it resides inside discourse and school structure. By 'human dimension', I mean both psychological and social factors, including life events that happen to impact learning. The basic design of the study consists of analysing primary qualitative data, respectively, in-depth interviews with ten students and four instructors from the Department of Sociology, Faculty of Sociology and Social Work, at Babeș-Bolyai University, ClujNapoca. The interviews are semi-structured, following an interview guide that breaks down high school experiences into understandable chunks. Thus, my aim is to explore and describe educational experiences by looking at multiple variables: time, teaching and learning styles, motivation, cultural capital, institutional practices, life circumstances and, most importantly, power flows between pupil and teacher/institution. These factors become part of the pupils' ways of learning, transforming the kind of engagement they have with knowledge 
and the educational provider. I insist on dividing the concept of learning from knowledge and the institution, making space for examples of it that fall outside of institutional management. Therefore, I consider events outside of school life into my analysis, in order to enlarge the images of acceptable learning experiences.

\section{Flows of power: teacher's discourses, structuring of curricular content and categorization of pupils}

It seems to be that most high schools have a similar mantra: learning is memorization, the teacher must give out information and the pupils must write it down and record it diligently in their brains. This fits well with the banking model Paulo Freire wrote about: knowledge is understood as something to be neatly packed and transmitted as intact by the knowledge-holders to the ignorant. The educational institution is in charge of determining what is to be known, how, when, and who is capable of delivering it. This is a power structure so obvious and legitimate that it goes hardly discussed anymore. However, it holds in itself various assumptions, one of which is that the pupil is not competent enough to determine his own learning practices: the pupil cannot choose the subject, the method of learning, nor the examination. He/she must submit to the decisions of institutions, come towards learning as it is shaped by it, and become a learner, have a 'learning self' that is directed by powers outside him/herself.

Had I realized earlier that what I thought about learning isn't like this, that learning isn't an obligation, that it must be a pleasure... I had come with the idea that you have to learn because you have to and it has to be hard because this means you are good. (DS., 3rd year student)

Learning is the 'job' of the pupil. Most of them have this discourse: they learnt because they had to, what else were they supposed to do? Whether they engaged with it seriously or less so was a different matter, but very few came to think they could build their own learning path in high school. The urgent discussion to be touched upon here is the large differences between high schools. Most of the interviewees spoke of having attended 'good high schools', sometimes, 'the best' in the region, however, this varies greatly. For one, what they thought of as a good high school was not always so by official standards (such as marks in the admittance or final exams). Secondly, and more importantly, 'best' high schools in one region can be of no comparison to 'best' high schools in a different region. Thus, disparities can be seen in the way these pupils relate to their high schools, in their narrative about learning, values and in their learning practices. In elite high schools, power operates through different 
means than in average, working-class high schools. The most obvious variation is in the need for discipline: elite high schools do not need to quiet their pupils - they are already quiet, attentive, ready to prove themselves -, while on the other side of the continuum, much of the teacher's authority is consumed in trying to control the pupil's behaviour. An illustrative example is this quote from a pupil in a village high school:

...if you are not interested in what I am teaching, at least don't make noise, take your phone, eat, but quietly, so we can talk to the interested people (MM., 2nd year student),

put next to a quote from a pupil in an elite, big city high school

everybody was asking a lot anyway, it was known you were at a good high school and you had to give your best... A class is good if it has great results, because everybody already had good marks, but they asked for more, to choose a topic and have achievements (DS., 3rd year student).

The elite high schools treat pupils much more often as rational actors that will act in their best interest, and push them to the limits because that is understood as their best interests. Other high schools tend to have a more explicitly paternalistic view, asking pupils to learn because that is their job (both the pupil's and the teacher's) and nudging them authoritatively (if they can) because pupils are not seen as capable of managing themselves.

Furthermore, it is not unusual to have an equalizing sign between the pupil's educational practices and the pupil's private self, these two being, at times, judged upon explicitly:

The teacher was very aggressive, she would get angry and reprehend you, ... she would reproach you personal stuff, why haven't you learnt, look how you haven't been a good pupil (MF., 2nd year student). The teachers, at maths, they always told us that we would never get anywhere, that we won't be able to do anything, we won't even pass our exams (BA., 1st year student).

It is not only inside the classroom that the movement and behaviour of pupils is being controlled, but also outside of it: the school gate can be closed and carefully guarded by a doorman who keeps an eye on who comes late or leaves early. Some schools endorse uniforms, marking their status. By some, a proper display of power is seen as a civilizing action, meant to teach young pupils how society works - there are hierarchies, there are social contracts, this is how the world is. This view seems to be also in line with a model of age-related behaviour: 
children act childishly, they should learn to act as adults. Once adulthood is reached (at least legally), it is time to ask of them to act as we have taught them. But is this really the case, when high school learning promotes compliance more often than not, while adulthood, whether as students or employees, requires the capacity to analyse a situation by yourself, define it and act upon it? When asked if they enjoyed high school, many of the interviewees said they didn't. The reasons were a combination of social inputs and educational disappointment. The ones who said they enjoyed it, usually enjoyed hanging out with their classmates, very few liked it for academic reasons. Not to say that they didn't like it at all, but, retrospectively, few argued that they really felt it has helped them substantially (in preparing for university, for the job market, or for a better self): 'If someone would ask me if I'd go back to high school, I'd say no.' (MF., 2nd year student)

Motivation is a driving force in learning, it can accelerate it to high speeds or slow it beyond the desirable limit. While it is not possible to determine what causes it exactly, one can follow its trail and see to what it is related. During high school, prevailingly, the motivation to learn is external: 'because one has to'. Learning is the pupil's job, his/her position in society, often compared to how the adult's job is 'to work'. The legitimate learning is the one provided by the institution, and other forms of it are alternatives to be put on second place (volunteering, learning a musical instrument, etc.). Pupils do take pleasure in learning during high school, but only at the subjects that they enjoy. Some disengage completely from other subjects, being interested in passing the exams only:

At the subjects I liked, I was motivated by the fact that they interested me. At tests, I wasn't very motivated, I learnt just to take a 5, 6 or 7. My mother, (she would gloss over it), but I accustomed her to it since 7th grade. Before I only had 10 s and I realized, what were they for? They were just marks (TS., 2nd year student),

but most of them dedicate a comparable amount of time to the subjects they dislike. Motivation, in high school, can also be internal, about finding and becoming oneself. Thus, pupils look for affirmation, trying to attain the status of 'being a good pupil':

...To prove myself I wasn't a bad pupil, I wasn't what people thought I was. I know some pupils make themselves visible and stay so, although they aren't always good, I also wanted to be visible, to be seen.... in 9th and 10th grade I avoided all that, they knew I learned ok, but although I did, I wasn't actively participating, for the teachers to know my name (MF., 2nd year student). 
There is common sense knowledge that pupils learn to have good marks. Insidiously, this has become absolutely normal, although marks were supposed to serve the function of telling how much a pupil has advanced, not be a target themselves. This can be most clearly seen when dealing with the baccalaureate, the final exam of high school, which is often a big part of the mark for entering university - and considered 'the maturity exam' socially, with a big emotional importance:

... I only learnt at the subjects I liked, English and Romanian. At the others I wasn't motivated, but at the end I was motivated by the BAC, the BAC was coming, so I learnt, not to fail it, but not aiming for a good mark ... I passed with 8, 8 something. For me, everything under 9 is not a high mark... (I didn't care for the high mark) because I knew I wouldn't go to university (LF., 2nd year student).

The rat race seems to continue: after learning for achieving a high mark at the BAC, one has to convert it into a valuable higher educational experience. The value of the high mark transforms into the possibility of entering a good university without paying, or, even better, with a scholarship. Thus, the act of learning continues to be monopolized by institutions that tame, structure and bend it, making it quantifiable and giving it an economic value. If one is in luck, a great teacher or a good choice of university can mend some of this:

He was one of the teacher that motivated you to learn, but not for the marks. He was an exception, the rest were more distant. (...) I still have this idea that I must (learn), a legacy from high school, but in general I really like the subjects we do here... In high school I learnt many things I didn't care about, because I had to, and I never questioned that I have to learn, that if I don't like it, I could not learn (DS., 3rd year student).

A key element of how institutionalized education happens is the aprioric, standardized structuring of the learning material. For once, it is neatly packaged and given to teachers for instruction. From there, each teacher transforms it according to his/her own self, being influenced by many variables, such as their own psychology and habitus, the school's policies and educational culture, what they believe to be good values and good knowledge, etc. The teacher is not a passive agent, but rather a maker of information, having the power to shape it in understandable bits or crippling it into boring, confusing, shattered pieces. This is why there are at least two levels in the transmission of knowledge from the institution to the pupil: first, pupils have to understand (or accept, without understanding) the logic of the programme as a whole, and second, pupils have to understand (or learn and accept, without understanding) the logic of the 
teaching act. While my analysis doesn't properly account for social class, it plays a very important role in the positions the pupil can take regarding school. Everyone has heard the meritocratic, social mobility discourse: if you learn well, you will do well, you will have access to better jobs, and live better (than your parents). However, at times, the amount of energy pupils put into high school, and, later on, into university, seems to be influenced by the horizon of possible future choices they can envision for themselves. If one knows his/her parents cannot support him/her through six years of architecture or medicine, then it is quite useless to even try to get in. The practicality of high school knowledge is thus questioned - if it doesn't teach you anything that makes you employable, why bother? '... I think this is how they thought, why learn this, what will it be useful for? I want to have money, to work - and it is understandable, given where they came from.', (TS., 2nd year student). For some pupils, there is an urgency to consider practical economic matters and thus find a job fast, while others, having more economic stability, can afford to find learning non-marketable knowledge acceptable (or even worthwhile). Pupils' positioning to the functionality of learning and the purposes of knowledge begins early, although not always consciously. Understanding the logic of teaching in daily classroom practice is thus of great importance. It takes a good teacher to make his own structures clear and easy to follow, as it is much easier to be incoherent: 'this teacher had a craze to dictate to us continuously, you couldn't understand, he kept jumping from one idea to the other ... it wasn't related, it was hard to keep up with him.' (BA., 1st year student). It's not a common teaching practice to share the plan of the lesson with the pupils, let alone ask for their input. Thus, making transparent the internal structure of teaching, ideally composed of the ordering of information in a logical manner, with a visible path in sight, and a reason for which to walk upon it, is not a frequent practice, according to my interviews. Not understanding the general reason of why any of the subjects are important makes them obsolete.

Until now I have disentangled how pupils position themselves in public education by navigating power flows that permeate their understanding of why they learn, their motivation and the structuring of the material. Furthermore, I want to touch upon how a hierarchical marking system can transform learning into a struggle for 'being better than the other'. While the amount of competition varies greatly in all my interviewee's high schools, when competitiveness is present, pupils begin to give more weight to the marks they receive, as they feel more defined by them. The belief in marks as true denominators of learning seems to create feud in the classroom ('...if someone took a higher mark, there was a kind of hate, what has he/she done?' MF., 2nd year student) and to feed the idea that learning is a block of things that can be counted and that one can have more of it than another ('I never considered myself good at school, it was weird, 
we were always comparing each other' MM., 2nd year student). At times, this means that there is a limited amount of space that can be occupied by good learners, as if knowledge itself is a gigantic turnip that we all take pieces from (some, smaller than others) instead of collaborating to get it out for all of us:

In middle school I started learning, after I stopped having problems at home, but also after the very good people left, and I stayed, I was level two, but I had a chance to be good, to be recognized (DS., 3rd year student).

If the high school was generally underperforming according to national standards, being capable of working with the system was not seen as desirable by fellow classmates: 'if you were just a bit smarter and interested you'd scandalize the lousy ones and conflicts would start ... the competition was stiff (MT., 3rd year student). This labelling can go further and create separate factions in a class, even if teachers only passively consider it truthful. It is not unknown, however, for teachers to thrust into designing their teaching according to it: '...they would divide us, if you were good you'd stay on one side and they'd give you stuff to do, if you were stupid you'd stay on the other side and didn't do much.' (BA., 1st year student). This model goes hand in hand with learning as simply memorizing.

This is not to say that competition cannot co-exist with deep learning, but rather to point out how the system functions: you learn to have good marks, which validate that you have learnt, and the way you have to learn for these high marks, most often in my interviewee's answers, is by following the script given by the teacher, which very rarely includes, for example, critical thinking. When not in elite high schools, the pupils who have engaged in an analysis of informational content were either out of school, acting on their own or with some parental advice, or under the guidance of one of the two or three exceptional teachers they knew. When asked how they learned in high school, they would say 'everything was to cram. To stay and read and repeat the information in your mind, and if you entered another context, you would forget it' (MF., 2nd year student).

A system that aims to label and categorize pupils also creates a new kind of knowledge about them, it sets up a place for them and it influences their self. Pupils have varying degrees of engagement with the institution's and teacher's discourses on their own position, and the belief in their truthfulness decreases often as they exit high school. In working class high schools, even good ones, teachers have more power over pupils and their subjectivity, while in elite high schools, parents tend to have a higher standing. An illustrative example is this quote: 
In high school I met the most authoritarian teachers. If you left classes they'd call your parents. One day I didn't come to school and they called mother and told her I didn't come, and she said she knew, so they started reprehending mother, for letting me not come to school (LS., 2nd year student).

Ivan Illich (2000) points this out very well in his writings: some teachers assume the role of a preacher or a therapist. For one pupil, this meant that at times the classroom would be a kind of confessional, where children could talk about their problems, especially after hours. For another, it meant always feeling spied upon and judged by teachers who, for example, would openly criticize certain pupils' romantic choices. In so called good high schools, moralizing is hidden behind a meritocratic discourse, and no one is openly called stupid, only made to feel that way. In high schools that do not have such a good standing, pupils are blatantly scolded, told they won't get anywhere if they keep it up like this, and told they are incapable. Teachers' understanding of pupils thus can engulf not only their educational lives, but their whole selves. Therefore, it is not surprising when this power to know more about someone than they know themselves is acted upon in a legitimate setting:

She has the impression that this one student doesn't know history, and she really didn't know so well because she was working, so she gave her a test and she passed it, but the teacher took it and said, you don't deserve to pass, so she gave her another test, in the same day, just for her, the first and the second, because she wanted to fail her. She didn't manage to fail her, so she'd examine her all the time, at the blackboard, but she said she was doing it to motivate her to learn for the BAC, to have a high mark' (DS., 3rd year student).

What this teacher knew so well regarding this particular pupil was even beyond tests of her own design, it seemed to be an instinct, a secret insight given by her position.

In high school, one of the major dimensions that keeps the distance between pupil and teacher is age-related categorisation. It feels simple and straightforward to put pupils in class by age, but when you start looking at it more carefully, there is little to say for how exactly one can determine all fifteen year olds have the same learning capacity just because of how long they have been alive. This age construct - adolescence - is both thought of as easily divisible and as very compact. For as long as you are in high school, even as you turn 18, teachers will still behave toward you with a protective, paternalist stance: '... there was always a hint of authority. During the breaks, there was this thing where they tried to be friendly, but to a limit, if you passed it, they would turn 
back to their class teacher self.' (MF., 2nd year student). Often, pupils are somehow considered both responsible and not competent enough to make the right choices. At this point, it makes sense that, when looking at good high schools where they are convinced learning is something to be taken very seriously, pupils themselves start to be keepers of this high standard. The exact practice here is 'marking the teacher'. The power flows in reverse, from the students who deem the teacher not competent enough. Students don't give real marks to teachers, however they label them very harshly according to how well they perform. While it doesn't happen often, it shows how power truly is something that doesn't reside in one person, but rather in institutional roles and the discourses about them. When the narrative of expertise is strong, and the idea of expertise is clear, whoever is not abiding to it, pupil or teacher, is bound to be admonished in one way or another:

We had a very unfit teacher, she wasn't prepared at all in English, and we were at the bilingual profile, advanced, and she would always give us B2 exercises, so we did an alternative protest, it was nasty ... she kept making mistakes and there were students who noted them and put them on the notice board (DS., 3rd year student).

As DS. quite clearly says, 'if a teacher was incompetent, he/she was dismissed very quickly. If he was very good, he was very respected.' DS. also speaks of the small, annoying, daily displays of unfair use of power some teachers acted through, such as asking for more than they had taught or reprimanding them for not being good enough of a class, although they had many students participating in national contests. This power struggle was not, however, creating unanimous solidarity within students. What is deemed as acceptable differs even in an environment with strong discourses on proficiency:

... not everyone agreed, there was this girl who rebelled against the math teacher, and half of the class was vexed, how can you talk to a teacher like that, [....] She told him she didn't think it was right to call students at the blackboard and make them feel anxious, because they cannot answer under that pressure. The teacher got mad, but the point is that she took a position and some agreed with her, some didn't (DS., 3rd year student).

Summing up, I would stress that in many Romanian high schools, there is a 'grab' on defining the pupil. Within this structure of power, what they have to learn, how and when, is determined outwardly. The definition of their role is given by others - they need to do what is asked (learn) and how it is asked (in time, for class, for tests). A specific kind of learning self is shaped: an obedient 
one, that is motivated externally, often treated paternalistically (or as a rational actor having already agreed with the given terms), and kept under control in both physical movement (during school time) and behavioural norms. The pupil is set into place in the learning institution by internalizing his hierarchy in class (both through marks and through the discourses teachers have about him/her). Furthermore, teachers sometimes act upon a special knowledge of the pupil, as when they choose the correct mark for him/her (just a bit bigger or lower than what standard calculations might bring) according to their previous convictions. To conclude, the learner is hardly free to define himself/herself as a learner by choice, and the way this category is conceived is often outside of his/her powers.

\section{Doing well, performing well: playing the role of the pupil}

It starts to become apparent that teaching can be done with the class, or against the class. In practice, that would mean either listening to what students might want, or pushing the official agenda very sternly, with no flexibility. As one interviewee says, 'if you have a student that wants to learn, let him learn!' (TS., 2nd year student). This can only become a piece of advice if it is a practice that teachers, through their actions, sometimes make it harder to learn, instead of easier. More accurately, this usually happens when knowing and respecting norms becomes more important than learning itself. Even further, respecting particular norms becomes learning, when dealing with certain tests, such as the BAC. 'Being a good pupil' is something that is played and learnt as a role in itself. The discourse on fairness is quite rare in high school, as most of them accept it as a given that certain pupils are just good, while others aren't. Sometimes this is signalled by high marks, other times by presence and activity in the classroom. Either way, there is a know-how of how to get into this special guild, one that some pupils never acquire, and once in there, your standing is secure, even if you still make mistakes:

'The teachers had a model of good learners and they wouldn't come out of it.... I felt it wasn't fair, if I did the same mistake as the 10 pupils, he was forgiven, but I would be reprehended, it wasn't fair and I felt it very strongly' (MF., 2nd year student), and 'she has a thing for pupils who weren't good enough, but with me she didn't, once I took an 8,3 and she marked it as 8,5, because I was a good student having a bad day' (DS., 3rd year student).

Knowing the good pupils from the others is another expression of the defining powers the teacher has. The teachers both believe in their tests and marks, and don't, because what is truly important is performativity. MF. and DS. bring poignant examples of that, with exposing that 'I had the impression I was a 
good student because I was answering and I was involved, active' and that, although one of them had learnt with the same preoccupation during all years of high school, she realized that to become a good student she would have to be 'active' and engaged during class.

Insight in how the educational system works in practice, in one's own high school, is necessary for passing through it successfully as a pupil. However, the kind of insight pupils acquire is of a certain type: it is about knowing how and when to show what they have learnt. As mentioned above, they learn certain norms of how to behave and how to perform, and they also learn how their own learning is judged upon, partly by marks, partly by teachers' observations. They rarely have an awareness of what exactly they will learn, although they are given the impression they have chosen it. In high school, and then in university, one chooses a profile, such as philology or maths. Most of them are convinced that they have signed a kind of social contract whilst knowing the terms, although this never happens (even if they look at the educational programme, it is impossible to guess exactly what third year courses will mean when you're not even in the first year, and, more importantly, you have no knowledge regarding how you will be taught). This appearance of choice can make them feel rather resigned about their learning paths, seeing them as already decided:

I wasn't so interested in the subjects of my first high school, but in my head, I had this idea, if I chose that profile, now stay there and learn what you are given. It's not like, I don't like physics, I don't go, I have to go, because I chose it, I had no reason to complain. I was a bit unhappy, but, well... (MM., 2nd year student).

What is, ultimately, very important for pupils to know, is how to handle being examined. This is another kind of inside knowledge of norms that happens gradually, without being pursued openly. One way to do this is to predict when you will be tested, as surprise tests are not common, and blackboard questioning has a pattern: 'you wouldn't learn for every class, you'd know when it was your turn, if you didn't have a mark, you'd suspect' (LF., 2nd year student). Testing is used, mostly, for categorizing purposes, and has little to no value otherwise. This can become disheartening, putting so much effort into something that is only meant to label you, with no other purpose whatsoever: 'We had three or four (projects) ... it was interesting, but at the end your work was thrown away, we constructed scale models, they costed money...' (MT., 3rd year student). Another practice that seems to spring up is marking from downwards, by signalling how much one doesn't know: 'if she saw you couldn't handle it, she asked you to read more, give your homework, and she'd give you a grade, if you handled it, she'd let you go' (MF., 2nd year student). These kinds of pressures can have the impact of transforming learning into something that is done under stress and supervision, out of fear of failing. 
There are three most obvious ways of coping with the pressures of such an educational system. The first way is disengagement, as much as it is acceptable. This means skipping classes when possible and not paying attention when in class, either chatting with friends, playing on the phone, reading something else, or 'sleeping, eating ... if I was sleeping I would only stand up to signal my attendance' (TS., 2nd year student). The second is copying or finding shortcuts, such as knowing very well how the teacher works, when to answer and how to get acceptable grades: 'we learnt before the tests, they would tell us when ...' (LF., 2nd year student). Copying, in particular, seems to be a way to manage doing well in a system in which you're not actually doing well at all. The third, and most ingenious, is hacking the boring material, picking at it until it becomes something that one can swallow or even enjoy: 'they were the books from schools, the ones we had to read. I was starting to see their good side, because everyone said they were boring, but I tried to see and get what I could from them.' (MM., 2nd year student).

The endpoint, what has even become, at times, the whole purpose of high school, is passing the baccalaureate. This exam, which the media loves to call 'the maturity exam', is actually a series of three exams and usually a language certificate. These depend on the profile of the high school, thus, most of my interviewees took it in Romanian, History and usually Geography. When approaching the time of the BAC, for short, teacher's behaviour change, everything becomes more serious, and preparations ensue. What has been taught in high school until then that has been marked with the words 'this will be part of the BAC' is suddenly recalled. Almost from the beginning of the last semester of 12th grade, most learning is reorganized, so as to have everyone's attention and energy preparing for this national exam, exactly the same for each and every pupil in the country:

With the Romanian language teacher, everything we did, even electives, we did Romanian language class... All the teachers' attention was towards this learning for the BAC, we had to pass it well so the high school would lookgood (MM., 2nd year student).

It so happens at times that, this baccalaureate supposed to fairly evaluate the knowledge accumulated throughout high school becomes the main reason to learn and shapes what has to be known: 'we had classes with him in 9th grade, it was easy, but now in 12th grade he was much harsher ... only then I really started to learn' (BA., 1st year student). How does the learning occur, more exactly? First, it varies greatly from pupil to pupil. There are some that truly only have to recall what they have already learnt and read, and thus do not need to dedicate it much 
time, although the general stressful atmosphere makes it seem like they should. There are others that plan to start early, such as in the summer before 12th grade, or in the winter before the last semester, but few stick to it. Most learning happens in the last few months, when teachers cram lots of exercises, repeating the exact form of the BAC's examinations with the pupils many times over. Some of the characteristics of the banking model of education make themselves apparent in BAC narratives, as pupils have internalized certain learning practices, such as the habit of being pressured and the need for competitiveness.

Finally, it is insight into how the system has to be 'played' that shows pupils how to do well. Given particular rules, roles and norms, pupils smartly pick them up and act accordingly: learning for the test is common, knowing when to put your hand up in class and when to expect examination. To cope with a system that asks too often for performance (as in playing a role), pupils might engage in (a) trying to ignore most of the tasks and simply skip as many as they can, (b) copying from others and finding other ingenious ways to pretend they have the desired knowledge, (c) picking at the learning material and rules until they convince themselves they can go through it, even the things they dislike. The subject that emerges from this kind of structure has a learning self that is shaped by waiting to be defined (not to self-define) and by looking for a way to play out what is asked of him/her.

\section{Learning and living: social relationships and hobbies}

School is a life-seizer, and it influences young people to shape themselves according to its programme. While some build a self that accepts education as a constitutive part of their personality, others put much more energy into other things, such as social or family aspects. In the following part I will explore some of the elements that have a high impact on learning, although institutionalized public education gives them little to no attention.

One crucial dimension of learning in schools is the social. The actors that meet in the educational setting, teachers and pupils, are humans with an important psychological and emotional social aspect. The fact that they practice education together with other people is hugely important and mostly unaccounted for in official discourse. In the interviewee's narratives, teachers are usually deposits of knowledge and technique, and the fact that pupils are not alone listening to its transmission is to be ignored, not benefited from. Group projects are rare and almost no one enjoys them anyway, because they usually tend to have work distributed unequally inside the team. The model is sometimes simple, akin to the mechanical model of communication, with a clear message to be received, sometimes more complicated, with improved teaching techniques 
(such as questioning and discussion). By design, there is little said regarding pupil-teacher relationships or pupil-pupil relationships, as if these were not essential features of the educational environment. Listening to interviewee's stories, however, it is clear that these play an important part in whatever learning takes place. Only one student mentioned that she didn't feel influenced at all by the teacher's personality or method, while the rest had memories of good or bad teachers that drove them towards or away from a certain subject. Some students stressed how studying in disorderly classrooms has been difficult, while others tell of how school has been so much fun exactly because of their mates.

There are a lot of pressures being put onto teachers. They have to know, perform and have a model behaviour. Incredible emotional and psychological stability and strength is asked of them just to do well, and a lot of creativity and passion to do really well. It is no wonder that not many are up for the task, and, when finding themselves with the power and responsibility of their position in hand, they slip or misuse it. Stories of abuse of power are very common and range from mild to severe misconduct. One small example would be to give spontaneous tests when the teacher is angry or for some other reasons doesn't want to deal with the pupils (one interviewee mentioned that they would usually get tests when the teacher's favourite football team lost). A more serious example would be targeting certain pupils, whether one does not like them personally (doesn't agree with their opinions, values, look) or one feels they must be pressured continuously to properly learn. One interviewee has an account of physical violence (being slapped for smoking in the school's bathroom), while another has a story of being methodically given smaller marks because of being generally disliked by the teacher ('he gave me three marks of three in three minutes because I didn't have the notebook with me, I even went out so he'd put an absence, and when I entered, during break, he gave them, because I had three subjects with him that year', TS., 2nd year student).

Much of the learning that happens in the years of adolescence goes unnoticed by the institution. It is not only a period of self-discovery and selfmaking, but also one of exploration, both for the social and the intellectual lives. The 'hobbies' that many pupils have are not seen as proper knowledge, even though it can happen that they become very good at those, and voluntary work is a side thing, even though it can teach citizenship and solidarity (while schools rarely even mention it). The legitimate institution should always be put first ('I did a lot of volunteering...my mother felt I didn't invest enough in high school, although I had good grades, just based on this difference, but then she came to school and saw that it was OK', TS., 2nd year student) and then the second place is often taken by its adjacent extracurricular projects (the Olympiads come first, but there are also school clubs). As a difference, an informal learning experience was described like this 
... learning by doing, you had freedom, you could learn and take what you want, nobody did evaluations on you in that sense, that you were either good or bad, we all did something, and besides, you weren't sitting from 8 in the morning on a chair reading, (TS., 2nd year student).

Thanks to the spread of the internet, a lot of learning can now be done by oneself, at home, and is done like this indeed ('I learnt English on my own, I learnt it from the internet...', MF., 2nd year student).

Finally, much of the structure of institutionalized high school learning in Romania seems to overlook the importance of social relationships. Targets and standards are set without truly accounting for the fact that it is social beings that teach and social beings that learn, coming from particular socio-economic context and having their own psychology and individuality. Firstly, while pupils place a lot of weight on the friendships they make in high school, these seem to not be taken into account when designing learning. Secondly, teachers themselves are put into a position of power that at times is difficult to handle and perform as desired. Thirdly, pupils do enjoy in many other forms of learning (such as hobbies) that are sometimes not considered legitimate enough and thus are pushed aside in favour of schooling - again, an act that hampers their self-definition and is a proof of the powerful grab the educational institution has on them.

\section{Conclusions}

The careful, detailed exploration of lived learning experiences in high schools has unravelled a map of narratives about how teaching is practiced and what impacts it has on the learning self and the relationship to knowledge. It has been shown that many high schools endorse a banking model of education, rewarding good memorizing and listening abilities, keeping a cold distance between the teacher and the pupil, using disciplinary techniques and defining the learning self. Disciplinary power is used openly in working class high schools to keep pupils in their seat and control their movements, and more subtly in elite high schools, to make pupils learn according to the institution's standards. Most pupils learn, most of the time, due to an extrinsic motivation, seeing schooling as their 'job' they rarely take pleasure in. The standardized packing of the content doesn't help much, making information often seem lifeless and useless beyond school walls. While understanding the purpose of schooling and the internal logic of each teacher's courses could be of much aid, it does not always happen, as there 
is little work done to make it transparent. Institutions aim to categorize the pupils and often succeed, as pupils can become, at times, quite competitive and start seeing knowledge as some 'thing' to have a bit more of than your peers. Even so, being a 'good pupil' has more to do with performing well and at the appropriate time, rather than memorizing all you are given. Insight in how the institution works and what each teacher asks is essential in passing, as well as knowing the right shape of answers to the form of the questions. Learning for the BAC is the peak symbol of this kind of educational system, as it requires proper understanding of instructions and abilities to reproduce from memory in order to pass. However, life also bulges into the neat fabric in which educational institutions have sewn learning into, showing that it has its own lessons to give. Teaching humans by humans cannot be seen as a technical transmission of information, as it obviously does not work that way. Both teacher and pupil/student have a self and a life outside of school that deeply influences what they can do inside of it. Finally, it should be understood that learning is also a process of transformation that meets other transformations pupils go through, and the increasing drive to institutionalize, measure, and set targets, will not lead to true improvement.

Writing and researching educational practices is a continuous process that requires reiteration. The question is, truly, how can we bring this knowledge where it is most needed, and how can we, by making the system's failings transparent, help create a better one. My study, although an exploration of recalled practices of a small number of individuals, wishes to play a part in showing what seems to work and what doesn't, and also how it does work and what kind of subjectivity it does produce. Hopefully, striving to see clearly and act responsibly will guide both educational research and reform in the very near future.

\section{REFERENCES}

Anyon, J. (1980). Social Class and the Hidden Curriculum of Work. Journal of Education, 162 (1): 67-92.

Bălățescu, S. (2009). Determinanți ai satisfacției cu școala. Studiu în rândul elevilor de liceu din Oradea. 'Educațiea și excluziunea socială a adolescenților din România', [Determinants of school satisfaction. Study amongst high school students in Oradea. 'Education and social exclusion of teenagers in Romania'], coord. by Adrian Hatos, Sorana Săveanu, Editura Universității din Oradea, pp. 215 - 227. 
Bourdieu, P. (1984). Distinction: A Social Critique of the Judgement of Taste. Harvard University Press.

Bloome, D., Puro, P., \& Theodorou, E. (1989). Procedural Display and Classroom Lessons. Curriculum Inquiry, 19 (3): 265-291.

Freire, P. (2000). Pedagogy of the Oppressed. New York: Bloomsbury Academic.

Foucault, M. (1995). Discipline and Punish: The Birth of the Prison. New York: Vintage Books.

Gaztambide-Fernández, R. (2011). Bullshit as resistance: justifying unearned privilege among students at an elite boarding school. International Journal of Qualitative Studies in Education, 24 (5): 581-586.

Giroux, H. (2011). On critical pedagogy. London: The Continuum International Publishing. Illich, I. (2000). Deschooling Society. London: Marion Boyars Publishers Ltd.

Iosifescu, C., Mihaila C., Munteanu M., Novak C., Petrescu C., Pop L. (2013). Studiu național privind stadiul dezvoltării culturii calității la nivelul sistemului de învățământ preuniversitar, [National study overseeing the stage of development of the culture of quality at pre-college level education], Agenția Română de Asigurare a Calității în Învățământul Preuniversitar, Bucuresti.

Stănciulescu, E. (2002). Despre tranziție și universitate, [On transition and university]. Iași: Polirom, 2002.

Vogel, S., Schwabe, L. (2016). Learning and memory under stress: implications for the classroom. Npj Science of Learning, 1 (11): 1-10. 